ORIGINAL ARTICLE

\title{
Patient and disease profile of emergency medical readmissions to an Irish teaching hospital
}

\author{
E D Moloney, K Bennett, B Silke
}

Postgrad Med J 2004;80:470-474. doi: 10.1136/pgmi.2003.017624

See end of article for authors' affiliations

Correspondence to

Dr B Silke, Department of

Pharmacology and

Therapeutics, Trinity

Centre for Health Sciences,

St James' Hospital, James'

Street, Dublin 8, Ireland;

silkeb@tcd.ie

Submitted

28 December 2003

Accepted

12 November 2003

\begin{abstract}
Objective: To determine whether there was a relationship between coded diseases at the time of hospital discharge, a pattern of ordering investigations, and hospital readmission in a major teaching hospital. Design: Systematic review of data relating to emergency medical patients admitted to St James' Hospital Dublin between 1 January and 31 December 2002.

Data sources and methods: Data on discharges from hospital recorded in the Hospital In-Patient Enquiry (HIPE) system. The value of HIPE data in describing the relationship between the pattern of resource utilisation, diagnostic related groups, and hospital readmission has not previously been examined.

Results: Of 5038 episodes recorded among 4050 patients admitted, the number of readmissions was up to 15. Age and male gender were factors associated with readmission, and readmitted patients remained in hospital for longer. No particular test request predicted readmission, but computed tomography of the brain was associated with a reduced readmission rate. Discharge diagnostic related group coding at first discharge predicted readmission - codes related to heart failure, respiratory system, alcohol, malignancy, and anaemia.

Conclusions: It was found that clinical coding using the HIPE database strongly predicted hospital readmission. It may be argued that early hospital readmission reflects unsatisfactory patient care, alternatively that many readmissions are not preventable, representing either new events in elderly patients with chronic illnesses and frequent co-morbidity or related to social factors. The utility of specific interventions, in patients at high risk for hospital readmission, could be explored.
\end{abstract}

$\mathrm{T}$ here has been a relentless increase in emergency medical admissions in the UK over recent years. ${ }^{12}$ After discharge from hospital, unplanned readmissions are relatively common, with reported rates of $15.1 \%$ at 28 days from North East Thames, ${ }^{3} 28 \%$ at three months in Edinburgh, ${ }^{4} 38 \%$ at six months in London, ${ }^{5}$ and $19.3 \%$ at one year from Belfast. ${ }^{6}$ The rising trend in emergency readmissions is worrying, partly because of implications about quality of care, but also because of the burden placed on the provision of acute hospital services. As length of inpatient stay reduces, scrutiny and monitoring of readmissions are increasingly relevant, particularly with the growing number of elderly patients requiring acute hospital care. The cost savings associated with shortened hospital stay are lost when patients are rehospitalised. However, many readmissions may not be preventable, representing fresh events in patients with chronic illnesses and frequent co-morbidity. Therefore, a better knowledge of risk factors should allow targeting of patients at high risk of hospital readmission and identify domains of possible action regarding preventive interventions during the initial hospitalisation. Data on discharges from acute public hospitals in Ireland are recorded in the Hospital In-Patient Enquiry (HIPE) system. Sixty hospitals participate in the system and it is an invaluable source of hospital activity level and accreditation. The principal objective of this study is to determine whether there is a relationship between a pattern of ordering investigations and diagnostic related groups at the time of discharge using the HIPE dataset, and hospital readmission, among patients admitted as emergencies to a general medical department of a teaching hospital in Dublin, Ireland.

\section{PATIENTS AND METHODS}

Data relating to emergency medical patients admitted to St James' Hospital between 1 January and 31 December 2002 were recorded. St James' Hospital, although a tertiary referral centre for various specialties, operates a daily sectorised acute general medical "take-in" serving as a secondary care centre for emergency medical admissions for its local Dublin catchment area. Patients were admitted directly to a variety of wards, many of which are not affiliated with a medical specialty, under the care of a named consultant physician. Fourteen different consultant physicians were responsible for the management of these patients of which 10 were whole time health service consultants and four held split service/ academic appointments. All had a major subspecialty interest as well as an acute general medical admissions commitment. These included respiratory medicine (4), gastroenterology (4), diabetes/endocrinology (2), clinical pharmacology (2), rheumatology (1), and cardiovascular medicine (1).

The 2002 patient database was acquired by linking the patient administration system to the HIPE. HIPE is a national database of coded discharge summaries from acute public hospitals in Ireland. Ireland has used the International Classification of Diseases, ninth revision, clinical modification (ICD-9-CM) for both diagnosis and procedure coding since 1990, with updates every five years. Sixty hospitals participate in the system; the computer based discharge abstracting system is designed to collect demographic, clinical, and administrative data on discharges and deaths from acute general hospitals. It is the only source of morbidity data available nationally for acute hospital services in Ireland. Linking the HIPE dataset with the patient administration system permits application of routinely collected data for the purposes of research, planning, and quality control. Data collected include hospital number; patient's name; dates of admission and discharge; date of birth; sex; area of residence

Abbreviations: CVA, cerebrovascular accident; HIPE, Hospital InPatient Enquiry; IQR, interquartile range 
Table 1 Percent readmissions by various patient and diagnostic factors (categorical variables)

\begin{tabular}{|c|c|c|c|}
\hline Variable & No & \% Readmission & p Value ${ }^{*}$ \\
\hline \multicolumn{4}{|l|}{ Gender } \\
\hline Male & 1946 & 16.4 & 0.043 \\
\hline Female & 2105 & 14.1 & \\
\hline \multicolumn{4}{|c|}{ Any psychiatric } \\
\hline Yes & 305 & 28.5 & $<0.0001$ \\
\hline No & 3746 & 14.1 & \\
\hline \multicolumn{4}{|c|}{ Any alcohol } \\
\hline Yes & 196 & 31.6 & $<0.0001$ \\
\hline $\begin{array}{l}\text { No } \\
\text { Any gastr }\end{array}$ & 3855 & 14.4 & \\
\hline \multicolumn{3}{|c|}{ Any gastrointestinal } & $<0,0001$ \\
\hline No & $\begin{array}{l}292 \\
3759\end{array}$ & $\begin{array}{l}27.4 \\
14.3\end{array}$ & 0.0001 \\
\hline \multicolumn{4}{|c|}{ Hypertension } \\
\hline Yes & 610 & 25.6 & $<0.0001$ \\
\hline No & 3441 & 13.4 & \\
\hline \multicolumn{4}{|l|}{ UTI } \\
\hline Yes & 245 & 24.5 & $<0.0001$ \\
\hline No & 3806 & 14.6 & \\
\hline \multicolumn{4}{|c|}{ Any pneumonia } \\
\hline Yes & 267 & 24.7 & $<0.0001$ \\
\hline No & 3784 & 14.5 & \\
\hline \multicolumn{4}{|c|}{ Any respiratory } \\
\hline Yes & 795 & 28.2 & $<0.0001$ \\
\hline No & 3256 & 12.0 & \\
\hline Any CHF, & & & \\
\hline Yes & 381 & 32.8 & $<0.0001$ \\
\hline No & 3670 & 13.4 & \\
\hline Any CVA & & & \\
\hline Yes & 296 & 19.9 & 0.0187 \\
\hline No & 3755 & 14.8 & \\
\hline Any synce & & & \\
\hline Yes & 183 & 16.4 & 0.647 \\
\hline No & 3868 & 15.2 & \\
\hline Atrial fibr & & & \\
\hline Yes & 357 & 28.0 & $<0.0001$ \\
\hline No & 3694 & 14.0 & \\
\hline Any neop & & & \\
\hline Yes & 272 & 21.0 & 0.0063 \\
\hline No & 3778 & 14.8 & \\
\hline Any coror & & & \\
\hline Yes & 337 & 20.5 & 0.005 \\
\hline No & 3713 & 14.7 & 0.005 \\
\hline Any anae & & & \\
\hline Yes & 138 & 25.4 & 0.0007 \\
\hline No & 3912 & 14.9 & \\
\hline Any diab & & & \\
\hline Yes & 300 & 16.3 & 0.573 \\
\hline No & 3750 & 15.1 & - \\
\hline OGD & & & \\
\hline Yes & 306 & 24.8 & $<0.0001$ \\
\hline No & 3745 & 14.4 & \\
\hline Injectable & & & \\
\hline Yes & 583 & 32.6 & $<0.0001$ \\
\hline No & 3468 & 12.3 & \\
\hline Pulmonar & & & \\
\hline Yes & 107 & 19.6 & 0.197 \\
\hline No & 3944 & 15.1 & \\
\hline ERCP & & & \\
\hline Yes & 94 & 13.8 & 0.71 \\
\hline No & 3957 & 15.2 & \\
\hline Cardiac u & & & \\
\hline Yes & 122 & 26.2 & 0.0006 \\
\hline No & 3929 & 14.9 & \\
\hline Vascular & & & \\
\hline Yes & 183 & 20.8 & 0.0321 \\
\hline No & 3868 & 14.9 & \\
\hline Abdomin & & & \\
\hline Yes & 388 & 29.9 & $<0.0001$ \\
\hline No & 3663 & 16.7 & \\
\hline Any MRI & & & \\
\hline Yes & 129 & 20.2 & 0.112 \\
\hline No & 3922 & 15.0 & \\
\hline MRI brain & & & \\
\hline Yes & 88 & 17.1 & 0.627 \\
\hline No & 3922 & 15.2 & \\
\hline $\mathrm{CT}$ thorax & & & \\
\hline Yes & 109 & 34.9 & $<0.0001$ \\
\hline No & 3942 & 14.7 & \\
\hline
\end{tabular}

Table 1 Continued

\begin{tabular}{llll}
\hline Variable & No & \% Readmission & p Value \\
\hline CT abdomen & 124 & 33.1 & \\
Yes & 3927 & 14.6 & $<0.0001$ \\
No & 942 & 17.6 & \\
CT brain & 3109 & 14.5 & 0.0184 \\
Yes & & \\
No & & \\
\hline
\end{tabular}

* $\chi^{2}$ test for comparisons between groups.

$\mathrm{CHF}$, congestive heart failure; $\mathrm{CT}$, computed tomography; CVA, cerebrovascular accident; ERCP, endoscopic retrograde

cholangiopancreatography; LVF, left ventricular failure; MRI, magnetic resonance imaging; OGD, oesophagogastroscopy; UTI, urinary tract infection.

by county; diagnosis-principal and up to nine additional secondary diagnoses; procedures-principal and up to nine additional secondary procedures; and consultant responsible for care. The HIPE dataset of all coded diseases at time of discharge/death, together with procedures and investigations undertaken during the in-hospital stay, was examined. Codes with fewer than 20 occurrences were not considered. Individual codings together with the combination of all related codes were evaluated.

\section{Statistical methods}

Descriptive analyses are presented in the form medians, interquartile range (IQR), proportions, and 95\% confidence intervals. A categorical variable was computed for each patient based on whether they had a single or multiple admissions. Associations were examined between continuous measures (age) and categorical measures using a nonparametric Wilcoxon rank sum test. Categorical measures were cross tabulated, and where appropriate $\chi^{2}$ tests performed. For the purpose of examining associations multivariately, backwards stepwise logistic regression was used to predict readmission. Odds ratios and 95\% confidence intervals are presented. Statistical significance at $\mathrm{p}<0.05$ is assumed throughout and a Bonferonni correction made for repeated statistical testing. All analyses were performed using the JMPin statistical package (version 3.2, SAS Institute Inc).

\section{RESULTS}

Five thousand and thirty eight episodes were recorded among 4050 patients admitted acutely via the emergency department in the calendar year 2002 (table 1). The number of readmissions were up to $15 ; 426$ patients $(10.5 \%)$ were admitted twice, $110(2.7 \%)$ on three, $35(0.9 \%)$ on four, and $24(0.6 \%)$ on five occasions. A further 21 patients $(0.5 \%)$ were admitted more than five times. The mean age of readmissions was 68.1 years (IQR 50.6-77.7) and was significantly older $(\mathrm{p}<0.0001)$ compared with patients admitted once only 63.7 years (IQR 41.8-77.0) (table 2). Readmissions were also more likely $(\mathrm{p}=0.04)$ to be male $(\mathrm{n}=319 ; 16.4 \%)$ than female $(\mathrm{n}=297 ; 14.1 \%)($ table 1$)$.

The median initial length of stay for readmitted patients was 8.3 days (IQR 4-15); this was significantly longer $(\mathrm{p}<0.0001)$ than that for those admitted once only (6 days; IQR 2-13). The readmission rate ranged from $12.0 \%$ to $20.7 \%$ between consultants and the frequency of readmission was significantly different $(\mathrm{p}=0.03)$.

There was little evidence of increased frequency of inpatient investigations/procedures in patients during a subsequent readmission. Compared with those having only one admission, the two investigations less frequently undertaken on a readmission were a pulmonary scan $(1.1 \% \mathrm{v}$ $2.5 \% ; \mathrm{p}=0.04)$ and computed tomography of the brain $(15.4 \%$ v 22.6\%; $\mathrm{p}<0.0001)$. Investigations more frequently 
Table 2 Median age (IQR) by readmissions

\begin{tabular}{llll}
\hline Variable & No & Median (IQR) & p Value $^{*}$ \\
\hline One admission & 3434 & $63.7(41.8-77.0)$ & $<0.0001$ \\
$>1$ admission & 616 & $68.1(50.6-77.7)$ & \\
\hline
\end{tabular}

undertaken in readmissions were computed tomography of the thorax $(3.6 \% \vee 2.1 \% ; \mathrm{p}=0.02)$ and abdominal ultrasound $(10.6 \% \vee 7.9 \% ; p=0.03)$. No association was noted for oesophagogastroscopy, endoscopic retrograde cholangiopancreatography procedures, any magnetic resonance imaging, cardiac or vascular ultrasound imaging (table 1).

Psychiatric codes included anxiety, depression, and psychosis and showed no association with increased frequency of hospital readmission.

A congestive heart failure $(11.0 \% v 5.6 \% ; \mathrm{p}<0.0001)$ or any heart failure coding $(13.8 \% \vee 7.5 \%$; $<<0.0001)$ was each associated with increased likelihood of an emergency hospital readmission. Respiratory system related codes associated with increased likelihood for readmission included chronic obstructive asthma without status code (18.0\% v 5.9\%; $\mathrm{p}<0.0001)$ or any respiratory diagnosis code $(28.6 \% \quad v$ $16.6 \% ; \mathrm{p}<0.0001$ ). There was no readmission propensity for diagnoses, on the first admission, of pneumonia or pneumococcal pneumonia while a non-specific respiratory diagnosis had a weak association code $(9.1 \% v 6.8 \% ; \mathrm{p}=0.05)$ (table 1$)$.

Gastrointestinal codes included epigastic pain, gastritis, gastrointestinal haemorrhage, haematemesis, and peptic ulcer; only a peptic ulcer diagnosis code $(2.9 \% \vee 1.6 \%$; $\mathrm{p}=0.03$ ) predicted readmission. The alcohol related codes were alcohol withdrawal, alcohol abuse, alcoholic fatty liver, alcohol liver damage, alcohol cirrhosis of liver, and alcoholic hepatitis. Only alcohol withdrawal $(1.5 \% \vee 0.4 \%$; $\mathrm{p}=0.005)$ and cirrhosis $(1.5 \% \vee 0.4 \% ; \mathrm{p}=0.006)$ were strongly associated with readmission; there was a trend for any alcohol diagnosis to be associated with a further admission $(5.7 \% \mathrm{v}$ $3.9 \% ; \mathrm{p}=0.04)($ table 1$)$.

All malignancy related codes of malignant neoplasm $(7.8 \%$ $v 5.2 \% ; \mathrm{p}=0.01)$, or any neoplasm $(9.3 \% v 6.3 \%$; $=0.006)$ predicted a further readmission.

Stroke related codes include transient ischaemic attack, cerebrovascular accident (CVA), CVA/infarct, and intracranial haemorrhage. These diagnoses either were not associated or predicted a decreased likelihood of a further readmission. A $\mathrm{CVA} /$ infarct $(4.0 \% v 1.8 \% ; \mathrm{p}=0.005)$ or any stroke diagnosis $(4.4 \% \quad v 6.9 \% ; \mathrm{p}=0.02)$ predicted a reduced readmission likelihood (table 1).

Coronary related codes included chest pain, atrial fibrillation, coronary atherosclerosis in native vessels, angina, and intermediate coronary syndrome. Chest pain $(0.7 \% \vee 1.8 \%$; $\mathrm{p}=0.04$ ) predicted a reduced readmission likelihood whereas angina $(2.9 \% \vee 1.6 \% ; \mathrm{p}=0.03)$, coronary atherosclerosis in native vessels $(8.6 \% \vee 6.1 \% ; \mathrm{p}=0.02)$, and any coronary related code $(11.2 \% \vee 7.8 \% ; \mathrm{p}=0.005)$ predicted an increased readmission likelihood (table 1 ).

Diabetes related codes included diabetes mellitus type 1 uncomplicated and type 2 uncomplicated; none were associated with a significantly altered readmission rate.

Anaemia related codes included iron deficiency anaemia non-specific $(3.1 \% \vee 1.8 \% ; \mathrm{p}=0.06)$ and anaemia nonspecific $(2.6 \% \vee 1.2 \% ; \mathrm{p}=0.03)$; both predicted increased readmission likelihood as did any anaemia diagnosis $(5.7 \% \mathrm{v}$ $3.0 \% ; \mathrm{p}=0.0007)$ (table 1$)$.

Codes of patients presenting with "funny turns" included syncope, dizziness and giddiness, and fits. Although neither syncope, nor dizziness and giddiness independently predicted
Table 3 Adjusted odds ratios (95\% confidence intervals) from logistic regression analyses predicting readmission

\begin{tabular}{|c|c|c|}
\hline Factor & Odds ratio & p Value \\
\hline Age (years, continuous) & & 0.004 \\
\hline \multicolumn{3}{|l|}{ Gender } \\
\hline Female $v$ male & $0.81(0.68$ to 0.98$)$ & 0.025 \\
\hline \multicolumn{3}{|l|}{ Any psychiatric } \\
\hline Yes $v$ no & $1.26(0.89$ to 1.74$)$ & 0.181 \\
\hline \multicolumn{3}{|l|}{ Any alcohol } \\
\hline Yes & 1.69 (1.12 to 2.49$)$ & 0.010 \\
\hline \multicolumn{3}{|l|}{ Any gastrointestinal } \\
\hline Yes & $1.01(0.68$ to 1.45$)$ & 0.973 \\
\hline \multicolumn{3}{|l|}{ Any pneumonia } \\
\hline Yes & $0.97(0.66$ to 1.39$)$ & 0.87 \\
\hline \multicolumn{3}{|l|}{ Any respiratory } \\
\hline Yes & 1.91 (1.54 to 2.36$)$ & $<0.0001$ \\
\hline \multicolumn{3}{|l|}{ Any CHF/LVF } \\
\hline Yes & 1.54 (1.15 to 2.06$)$ & 0.004 \\
\hline \multicolumn{3}{|l|}{ Any CVA } \\
\hline Yes & $0.76(0.47$ to 1.17$)$ & 0.222 \\
\hline \multicolumn{3}{|l|}{ Any neoplasm } \\
\hline Yes & 1.47 (1.04 to 2.04$)$ & 0.027 \\
\hline \multicolumn{3}{|l|}{ Any coronary } \\
\hline Yes & $1.23(0.91$ to 1.65$)$ & 0.17 \\
\hline \multicolumn{3}{|l|}{ Any anaemia } \\
\hline Yes & 1.78 (1.17 to 2.65$)$ & 0.006 \\
\hline \multicolumn{3}{|l|}{ Cardiac ultrasound } \\
\hline Yes & $0.89(0.49$ to 1.53$)$ & 0.69 \\
\hline \multicolumn{3}{|l|}{ Vascular ultrasound } \\
\hline Yes & $1.07(0.66$ to 1.65$)$ & 0.79 \\
\hline \multicolumn{3}{|l|}{ Abdominal ultrasound } \\
\hline Yes & 1.36 (1.0 to 1.83$)$ & 0.045 \\
\hline \multicolumn{3}{|l|}{ OGD } \\
\hline Yes & $0.91(0.62$ to 1.30$)$ & 0.606 \\
\hline \multicolumn{3}{|l|}{ Injectable antibiotic } \\
\hline Yes & $0.98(0.74$ to 1.28$)$ & 0.87 \\
\hline \multicolumn{3}{|l|}{$C T$ thorax } \\
\hline Yes & $1.37(0.78$ to 2.31$)$ & 0.250 \\
\hline \multicolumn{3}{|l|}{ CT abdomen } \\
\hline Yes & $0.93(0.58$ to 0.97$)$ & 0.795 \\
\hline CT brain & & \\
\hline Yes & 0.75 (0.58 to 0.97$)$ & 0.0322 \\
\hline
\end{tabular}

$\mathrm{CHF}$, congestive heart failure; $\mathrm{CT}$, computed tomography; CVA, cerebrovascular accident; LVF, left ventricular failure; OGD, oesophagogastroscopy.

a reduced readmission likelihood, their combination as any syncope predicted a reduced likelihood $(2.4 \%$ v $4.5 \%$; $\mathrm{p}=0.02)$. Fits were not statistically related to likelihood of readmission (table 1 ).

The main factors of interest $(p<0.10$ in univariate analyses) were studied simultaneously with multivariate logistic regression analysis; table 3 presents adjusted odds ratios (with 95\% confidence intervals). This analysis shows that age, male sex, a previous admission, and each of the following diagnostic categories-respiratory related, heart failure, alcohol, neoplasm, or anaemia-were more predictive for readmission. Investigations on the index admission did not predict readmission; computed tomography of the brain appeared to reduce the readmission rate.

\section{DISCUSSION}

The acute general medical readmission rate in our study for the calendar year 2002 was $15.2 \%$, with a range of $12 \%$ to $20.7 \%$ between consultants. Age and male gender were factors associated with readmission to hospital, and readmitted patients remained in hospital for longer. No test request predicted readmission, but computed tomography of the brain performed on the initial admission was associated with a reduced readmission rate. Moreover, readmission was associated with the following diagnostic related group coding at discharge: heart failure codes, respiratory system codes, alcohol related codes, malignancy related codes, and anaemia related codes. 
We linked the hospital patient administration system and HIPE data set to define a clinically useful database relating to emergency medical readmissions. Given the costs associated with such data collection, there is considerable literature utilising these types of data, and supporting its use for research, planning, and monitoring purposes. ${ }^{89}$ However, concerns over HIPE coding are longstanding with complex clinical documentation, inexperienced coding personnel, and illegible handwritten medical record entries all contributing to inaccurate classification. ${ }^{10-12}$ The Department of Health uses HIPE data and hospital financial information from the Specialty Costing system to measure and compare hospitals' performance. The case mix directly influences funding given to a hospital, with more efficient hospitals being rewarded at the expense of the less efficient. Therefore, improvement in the quality of clinical coding is a desired goal to make such comparisons more meaningful and to provide a firm basis for both clinical and management decisions. In our study we found that the HIPE database was very powerful in predicting readmissions to hospital.

Recent years have seen rises in readmissions both in the $\mathrm{UK}^{12}$ and the USA. ${ }^{13}$ The increasing number of elderly people in the population may be particularly important in generating the rise because admission rates increase dramatically with age, ${ }^{414}$ especially in those living alone. ${ }^{4}$ Others have also found that males are more commonly readmitted than females, ${ }^{15-17}$ and have postulated that this is due to the greater disease severity and higher mortality in men compared with women of the same age. ${ }^{17}$

Hospital readmissions are considered to be a significant outcome indicator, because they reflect the impact of hospital care on the condition of the patient after discharge, and high readmission rates are sometimes considered to be the price for shorter inpatient stays. ${ }^{7}$ Moreover, from a financial standpoint, readmissions involve returns for the most expensive type of health services, inpatient acute care. ${ }^{18-20}$ Previous studies, however, have shown relapses of an underlying medical problem to be responsible for the majority of emergency readmissions, and that significantly more patients with chronic disabling conditions are readmitted than others. ${ }^{51-26}$ A comparative analysis of hospital readmission rates in three European countries and three states in the USA found that diagnoses such as chronic obstructive pulmonary disease and heart failure were the major causes of hospital readmission. ${ }^{27}$ In this study, initial hospital stays were generally longer for patients who were readmitted than for those who were not, suggesting that hospital readmissions were not produced by premature hospital discharges. ${ }^{27}$ This suggests that the use of the emergency readmission rate as an outcome indicator intended to reflect quality of care is not necessarily valid.

The patterns, prevalence, risk factors, and predictors of early hospital readmission have been examined in series from many countries and health care systems. The overall standardised emergency readmission rate for teaching trusts throughout Scotland over a four year period, in all medical specialties, was $10.9 \% .^{23}$ The principle causes of emergency readmission varied, but leading causes included poisoning and heart disease. The majority of emergency readmissions occurred in patients with an underlying chronic condition, and many had a history of multiple previous hospital admissions. ${ }^{23}$ A further study of 1204 elderly patients discharged from hospital found that $37.7 \%$ had at least one readmission in six months. Recurrent readmission was predicted by poor family support, residence in a home for the elderly, and unresolved medical problems. ${ }^{24}$

Others have studied the incidence and profile of elderly patients requiring early unplanned readmission within 15 days of discharge from a regional hospital. The readmission rate was $9.2 \%$, and factors predictive of readmission were the number of medical problems and number of previous admissions. ${ }^{28}$ Similarly, the readmission characteristics of elderly patients after inpatient rehabilitation in Northern Ireland was reviewed. ${ }^{29}$ The overall readmission rate at 30 days was $15 \%$, at 90 days $24 \%$, and at 180 days, $30 \%$. On some occasions readmission was deemed avoidable by the general practitioner, with most citing avoidable failures in communication and discharge planning as reasons for readmission. ${ }^{29}$

A multicentre study looked at the non-elective readmission rate within 90 days of discharge from hospital. ${ }^{30}$ Of 1378 patients discharged, 23.3\% were readmitted within 90 days. Risk of readmission was increased if the patient had more hospitalisations and emergency room visits in the previous six months, higher blood urea nitrogen, lower mental health function, a diagnosis of chronic obstructive pulmonary disease, and increased satisfaction with access to emergency care assessed on the initial hospitalisation..$^{30}$ Others identified three patient characteristics that were independent predictors of early readmission for elderly patients including a need of help with mobility, a negative answer to the question "do you feel that your life is empty?", and a short length of hospital stay. ${ }^{31}$

The respective frequency of planned and unplanned readmissions from a department of internal medicine has been compared. ${ }^{32}$ Unfortunately, whether a readmission was planned cannot be routinely determined from most hospital databases. In this study, of 5828 patients discharged, 12.5\% were readmitted within 31 days with slightly more planned than unplanned readmissions. Increased risk of unplanned readmission was associated with initial length of hospital stay longer than three days, an increased number of comorbidities, and with a diagnosis of neoplastic disease.

A study of elderly stroke patients found that stroke unit treatment was not associated with significant reductions in readmission rates as compared with treatment in general wards. ${ }^{33}$ Similarly, the readmission rate in patients discharged from a general medical unit was similar to that observed in patients discharged from a geriatric unit. ${ }^{16}$ It has been suggested that the standard of discharge planning is consistently better in geriatric units than in general medicine. ${ }^{34}$ However it has never been proven that better discharge planning prevents readmissions, although clearly it may make for a smoother transfer back to the community.

Patients leaving hospital against medical advice is a frequent occurrence that may be inversely related to socioeconomic status. ${ }^{35}$ A study of 97 consecutive patients who left the hospital against medical advice found they were much more likely than control patients to be readmitted within 15 days. Among the patients who left against medical advice, being male and having a history of alcohol abuse were significant predictors of readmission. ${ }^{35}$ Others found that younger age, male gender, and lack of a personal attending physician at the time of admission increased the odds of discharge against medical advice. ${ }^{36}$

One potential method for reducing the rate of readmissions is more frequent outpatient clinic review of patients after discharge. A study of two consultant general physicians with the same patient case mix but markedly different outpatient follow up practice has been described ${ }^{37}$ One consultant saw twice as many patients in the follow up clinic than the other, but the readmission rate between the consultants was similar. ${ }^{37}$ In terms of health care resources, these data would not support the hypothesis that increasing the proportion of patients followed up in a hospital general medical outpatient clinic would reduce the demand for acute hospital beds. However as approximately $50 \%$ of follow up appointments were made for more than six weeks after discharge, some 
uncertainty regarding the effectiveness of outpatient follow up on the early hospital readmission rate must remain.

In our study we found that clinical coding using the HIPE database was very powerful in predicting readmissions to hospital. The rising trend in emergency readmissions is important because of the burden placed on the provision of acute hospital services. However, many readmissions may not be preventable, representing fresh events in elderly patients with chronic illnesses and frequent co-morbidity. As several patient characteristics influence the risk of unplanned readmission, case mix adjustments may be necessary when readmission rates are compared between institutions or tracked over time. Moreover, a direction for further research would be to evaluate high risk patients for specific interventions for their disease conditions at discharge.

\section{Authors' affiliations}

E D Moloney, B Silke, Division of Internal Medicine, St James' Hospital, Trinity College Dublin, Trinity Centre at St James' Hospital, Dublin, Ireland

K Bennett, Department of Therapeutics and Pharmacology, Trinity Centre at St James' Hospital, Dublin, Ireland

\section{REFERENCES}

1 Goldacre MJ, Simmons H, Henderson J, et al. Trends in episode based and person based rates of admissions to hospital in the Oxford record linkage study area. BMJ 1988;296:583-5.

2 Henderson J, Goldacre MJ, Graveney MJ, et al. Use of medical record linkage to study re-admission rates. BMJ 1989;299:709-13.

3 Chambers M, Clarke A. Measuring re-admission rates. BM 1990;301:1134-6.

4 Tierney AJ, Worth A. Re-admission of elderly patients to hospital. Age Aging 1995;24:163-6.

5 Victor C, Jeffries S. Are re-admission rates a useful indication of outcome? Geriatric Med 1990;March:19-20.

6 Kelly JF, McDowell H, Crawford V, et al. Re-admission to a geriatric medical unit: is prevention possible? Ageing Clin Exp Res 1992;4:61-7.

7 Jones J. Re-admission rates: the price of early discharge. Health Serv J 1986;96:825.

8 Bain MR, Chambers JW, Brewster DH. Routinely collected data in national and regional databases - an underused resource. J Public Health Med 1997; 19:413-8.

9 Berkelman RL, Buehler JW. Public health surveillance of non-infectious chronic diseases: the potential to detect rapid changes in disease burden. Int J Epidemiol 1990;19:628-35.

10 Macintyre CR, Ackland MJ, Chandraraj EJ, et al. Accuracy of ICD-9-CM codes in hospital morbidity data, Victoria: implications for public health research. Aust N Z J Public Health 1997;21:477-82.

11 O'Neill B. The hospital in-patient enquiry scheme-a study of data accuracy. Ir Med J 1982;75:238-9.
12 Smith MW. Hospital discharge diagnoses: how accurate are they and their international classification of disease (ICD) codes? N Z Med J 1989; 102:507-8.

13 Saltz CC, McVey $\sqcup$, Becker PM, et al. Impact of a geriatric consultation team on discharge placement and repeat hospitalisation. Gerontologist 1988;28:344-50.

14 Kendrick S. The pattern of increase in emergency hospital admissions in Scotland. Health Bull 1996;54:169-83.

15 Mclnnes EG, Joshi DM, O'Brien TD. Failed discharges: setting standards for improvement. Geriatric Med 1988;April:35-42.

16 Gooding J, Jette AM. Hospital re-admission among the elderly. J Am Geriatr Soc 1985;33:595-601.

17 Graham H, Livesley B. Can re-admissions to a geriatric medical unit be prevented. Lancet 1983;i:404-6.

18 Anderson G, Steinberg E. Hospital re-admissions in the Medicare population. $N$ Engl J Med 1984;311:1349.

19 Hennen J, Krumholz H, Radford M, et al. Re-admission rates, 30 and 365 days post-discharge. Conn Med 1995;59:263-70.

20 Walter R. The revolving door of hospital re-admissions. Caring 1998; 17:56-9

21 Gautam P, MacDuff C, Brown I, et al. Unplanned re-admissions of elderly patients. Health Bull 1996;54:449-57.

22 Victor CR, Vetter NJ. The early re-admission of the elderly to hospital. Age Aging 1985; 14:37-42.

23 Leng GC, Walsh D, Fowkes FG, et al. Is the emergency re-admission rate a valid outcome indicator? Qual Health Care 1999;8:234-8.

24 Kwok T, Lau E, Woo J, et al. Hospital re-admission among older medical patients in Hong Kong. J R Coll Physicians Lond 1999;33:153-6.

25 Dai YT, Wu SC, Weng R. Unplanned hospital re-admission and its predictors in patients with chronic conditions. J Formos Med Assoc 2002;101:779-85.

26 Colledge NR, Ford MJ. The early hospital re-admission of elderly people. Scott Med J 1994;39:51-2.

27 Westert GP, Lagoe RJ, Keskimaki I, et al. An international study of hospital readmissions and related utilisation in Europe and the USA. Health Policy 2002;61:269-78.

28 Au SY, Chan KM, Chan YH, et al. Early unplanned re-admission of elderly in Singapore: a retrospective study. Ann Acad Med Singapore 2002;31:738-44.

29 Haines-Wood J, Gilmore DH, Beringer TR. Re-admission of elderly patients after in-patient rehabilitation. Ulster Med J 1996;65:142-4.

30 Smith DM, Giobbie-Hurder A, Weinberger $M$, et al. Predicting non-elective hospital re-admissions: a multi-site study. J Clin Epidemiol 2000:53:1113-8.

31 Peres K, Rainfray M, Perrie N, et al. Incidence, risk factors and adequation of early re-admission among the elderly. Rev Epidemiol Sante Publique 2002; 50:109-19.

32 Kossovsky MP, Perneger TV, Sarasin FP, et al. Comparison between planned and unplanned re-admissions to a department of internal medicine. J Clin Epidemiol 1999;52:151-6.

33 Claesson L, Gosman-Hedstrom G, Fagerberg B, et al. Hospital re-admissions in relation to acute stroke unit care versus conventional care in elderly patients the first year after stroke. Age Aging 2003;32:109-13.

34 Victor CR, Vetter NJ. Preparing the elderly for discharge from hospital: a neglected aspect of patient care. Age Aging 1988;17:155-63.

35 Hwang SW, Li J, Gupta R, et al. What happens to patients who leave hospital against medical advice? CMAJ 2003;168:417-20.

36 Weingart SN, Davis RB, Phillips RS. Patients discharged against medical advice from a general medicine service. J Gen Intern Med 1998;13:568-71.

37 Rayner HC, Temple RM, Marshall T, et al. A comparison of hospital readmission rates between two general physicians with different outpatient review practices. BMC Health Serv Res 2002;2:12 